\title{
PENGARUH PERILAKU KEBERAGAMAAN SISWA TERHADAP BUDAYA MULTIKULTURAL SEKOLAH ISLAM DI SD ISLAM AL-IKHLAS CILANDAK JAKARTA SELATAN
}

\author{
Nurjaya \\ Universitas Pamulang \\ Jayaalix03@gmail.com
}

Naskah diterima: 25 November 2019, direvisi: 30 November 2019, disetujui: 22 Desember 2019

\section{Abstrak}

Penelitian ini bertujuan untuk mengetahui pengaruh perilaku keberagamaan siswa terhadap budaya sekolah multikultural di SD Islam Al-lkhlas Cilandak Jakarta Selatan. Pendidikan Islam bertujuan untuk menanamkan nilai-nilai keberagamaan dalam perilaku dan kepribadian siswa, Sistem pembelajaran Pendidikan Agama Islam merupakan sistem pembelajaran yang berbeda dengan sistem pembelajaran pendidikan umum dan pendidikan diklat lain. sehingga berbagai kegiatan yang telah menjadi kebiasaan di sekolah tidak terlepas dari nilai-nilai agama.

Adapun pengolahan hasil penelitian ini dilakukan dengan menggunakan statistik deskriftif untuk mendapatkan estimasi data, setiap variabel penelitian dan nilai-nilai yang meliputi data skor, median, modus, simpangan baku, dan distribusi frekuensi.

Kemudian untuk keperluan hipotesis pengujian penelitian digunakan statistik inferensial dengan teknik regresi dan korelasi sederhana. Dari penelitian yang dilakukan, dapat disimpulkan bahwa: Pertama, terdapat hubungan positif dan signifikan antara budaya sekolah (school culture) dengan perilaku keberagamaan, yang dibuktikan dengan perolehan koefesien korelasi $\left(r_{y}\right)$ sebesar 0,962. Kedua, terdapat hubungan positif dan signifikan antara sikap multikultural dengan perilaku keberagamaan peserta didik, yang dibuktikan dengan perolehan koefesien korelasi $\left(r_{y}\right)$ sebesar 0.969. Ketiga, terdapat hubungan positif dan signifikan antara budaya sekolah dan sikap multikultural secara bersama-sama dengan perilaku keberagamaan, yang dibuktikan dengan perolehan koefesien korelasi $\left(r_{y 12}\right)$ sebesar 0,973 dan uji keberartian $F_{\text {hitung }}$ sebesar 1099,684.

Kata Kunci : Multikultural, Perilaku Keberagamaan Siswa 


\section{Pendahuluan}

Islam sebagai agama samawi yang diturunkan Tuhan kepada umat manusia di semesta ini pada prinsipnya mengandung perintah positif.Perintah positif yang ada dalam Islam sudah diyakini lebih dari XV abad yang lalu.'Pada masa itu Allah SWT.menurunkan seorang Nabi dan Rasul terakhir, Muhammad lbn 'Abdillâh. Nabi Muhammad SAW. pun dalam menyampaikan ayat-ayat kitâbullâh dengan metode atau cara yang rahmat (positif), sebagaimana Allah SWT. ketika menyampaikan kalam-Nya di Alqur'an. Ayat-ayat dalam Alqur'an sendiri, jika diteliti dengan seksama, maka akan didapati ayat-ayat mengandung hal positif. Jika ada ayatayat yang 'berbau' negatif pun tidak lain

'Tentang hal ini, Lihat, M. Quraish Shihab, Membumikan Al-quran: Fungsi dan Peran Wahyu dalam Kehidupan Masyarakat (Bandung: Mizan, Cet. ke-XIII, 1996), 21, 100. Lihat, Alqur'an surat (15/Al-Hijr) ayat 9; QS. 14 ayat 1; Atau lihat, M. Quraish Shihab, Mukjizat Alquran: Ditinjau dari Aspek Kebahasaan, Isyarat Ilmiah, dan Pemberitaan Gaib (Bandung: Mizan, Edisi ke-ll, 2013), 45-50, 60; Muhammad Sulaiman, Al-Burhân 'Ala Wahy Alqur'an, diterjemahkan oleh Muhammad Habib $M$. dengan judul, Menyanggah Keraguan Terhadap Alqur'an (Solo: Ramdhani, 1989), 11; Moenawar Kholil, Al-qur'an dari Masa ke Masa (Solo: Ramdhani, Cet. ke-Vll, 1994), 59; Abduddin Nata, Alqur'an dan Hadits: Dirasah Islamiyyah I (Jakarta: RajaGrafndo Persada, Cet. ke-V, 1996), 59; Syahrin Harahap, Islam Dinamis: Menegakkan Nilai-Nilai Ajaran Alqur'an dalam Kehidupan Modern di Indonesia (Yogyakarta; Tiara Wacana, 1997), 35, Abdul Aziz,Menangkal Islamofobia Melalui Re-Interpretasi Alqur'an Vol. Jurnal Al-Ar'af, XIII, No. 1, Januari - Juni 2016 hanyalah larangan (nahî) dari Allah, agar manusia tidak tersesat dari jalan yang lurus.

Kehidupan beragama di Indonesia akhir-akhir ini mendapatkan sorotan dari berbagai pihak. Baik dari dalam negeri sendiri, maupun dari luar.Hal ini tak lepas dari terus bermunculannya konflik sosial berlatarbelakang agama di tengah masyarakat. Mulai dari kasus penistaan agama, perusakan rumah ibadah, ujaran kebencian di media social dan saling mendiskreditkan antara satu umat dengan umat yang lain. Menjamurnya fenomena-fenomena ini mau tidak mau semakin mempertajam sentimen keagamaan di Indonesia. Sebagai akibatnya, kerukunan dan rasa kekeluargaan sebagai satu bangsa menjadi renggang dan terkotak-kotak berdasarkan agama dan kepercayaan masingmasing.Ironisnya, sebagian besar aktor-aktor konflik tersebut adalah umat Islam.

Kenyataan ini tak bisa diabaikan begitu saja, karena menyangkut masa depan nasionalisme dan keutuhan negara. Sebuah ironi, di tengah semakin ketatnya persaingan global, Indonesia justru akhir-akhir ini disibukkan dengan urusan "rumah tangga". Persoalan yang sebenarnya tak perlu diberdebatkan justru menjadi penyita perhatian dan 
penutup mata terhadap persoalanpersoalan besar yang dihadapi Indonesia ke depan.

Konflik-konflik sosial berlatarbelakang agama sebagaimana disinggung di atas, jika ditelisik sebenarnya berakar dari kegagalan dalam mendialogkan pemahaman agama dengan realitas sosial di Indonesia yang beragam, plural dan multikultural. Hal ini terutama dialami oleh kelompokkelompok garis keras yang tidak mau mentolelir dan sulit berkompromi dengan pemahaman agama lain yang berbeda. Bagi mereka, beragama yang benar adalah beragama yang seperti mereka lakukan.Sikap dan pemahaman ini didukung dengan realita bahwa Islam menjadi agama mayoritas di Indonesia.

Kasus yang cukup representatif mengenai hal ini adalah kekerasan yang dialami oleh kelompok Syiah di Sampang Madura.Kasus ini berdampak pada terusirnya kelompok minoritas Syiah dari tempat tinggalnya, Desa Karangganyam, Kecamatan Omben, Kabupaten Sampang.lva Hasanah dan Abdul Fatah (2015: 243) Kasus tersebut bukanlah kasus yang terjadi secara tibatiba.Praktik kekerasan yang dialami oleh komunitas Syiah di Sampang telah terjadi sejak tahun 1980.Rentetan kekerasan berlangsung lama hingga memuncak pada penyerangan di bulan Agustus 2012, yang memakan korban jiwa dan harta benda. ${ }^{2}$

Kasus lain yang juga mejadi sorotan publik bahkan mancanegara adalah kasus penodaan agama yang dilakukan oleh mantan Gubernur DKI Jakarta, Basuki Tjahaya Purnama atau Ahok tahun 2016 lalu. Kasus ini berawal dari pernyataan Ahok ketika melakukan kunjungan kerja di Kepulauan Seribu pada 27 September 2016, ia berkata: "Jadi jangan percaya sama orang, kan bisa saja dalam hati kecil Bapak Ibu nggak bisa pilih saya, ya kan. Dibohongin pakai surat al-Maidah ayat 5l, macem-macem itu. Itu hak Bapak Ibu, jadi Bapak Ibu perasaan nggak bisa pilih, nih, karena takut masuk neraka, dibodohin gitu, ya?'B

Menurut Moch Nur lchwan (2016: 96) Pernyataan Ahok tersebut kemudian diedit oleh Buni Yani dengan menghilangkan kata "pakai" lalu diunggah dalam dinding Facebooknya

\footnotetext{
${ }^{2}$ lva Hasanah dan Abdul Fatah, "Suara Simpang Kasus Sampang: Konflik Sunni-Syi'ah Perspektif Perempuan, (Yogyakarata: Program Studi Agama dan Lintas Budaya" dalam Mohammad lqbal Ahnaf dkk (ed.), Praktik Pengelolaan Keragaman di Indonesia Kontestasi dan Koeksistensi, (Center for Religious and Cross-cultural Studies/CRCS) Sekolah Pascasarjana, Universitas Gadjah Mada, 2015), 243.

${ }^{3}$ Moch Nur Ichwan, "MUl, Gerakan Islamis dan Umat Mengambang”, Maarif Vol. II, No. 2 Desember (Jakarta: Maarif Institute for Culture and Humanity, 2016), 96
} 
pada 6 Oktober 2016. Buntut dari unggahan Buni Yani tersebut adalah terjadinya gerakan Aksi Bela Islam pada 14 Oktober, 4 November, dan 2 Desember 2016. Jumlah peserta gerakangerakan ini mencapai jutaan (ada yang mengatakan tujuh jutaan, ada pula yang mengatakan 2,3 jutaan). Sebagai akibat dari kasus ini, hubungan antara umat Islam dan umat Kristen kembali memanas.Bahkan tidak hanya itu sentimen terhadap warga keturunan Tionghoa pun ikut-ikutan memanas.Muaranya, di berbagai media sosial bermunculan postingan-postingan yang bernada hujatan, cacian, dan ujaran-ujaran kebencian yang saling mendiskreditkan antar umat beragama.

Sementara

menurut

$\operatorname{Bagir}^{4}{ }^{4}$ (2015: v) setidaknya ada tiga hal yang menjadi faktor penyebab terjadinya konflik-konflik sosial berlatar belakang agama di Indonesia; pertama, sebagai negara demokrasi dengan mayoritas penduduk memegang teguh identitas keagamaan kontestasi untuk mendorong peran agama di ruang publik tidak terhindarkan. Kedua, terdapat beragam tingkat kemampuan

\footnotetext{
"Zainal Abidin Bagir, "Pengantar" dalam Mohammad lqbal Ahnaf dkk. (ed.), Praktik Pengelolaan Keragaman di Indonesia Kontestasi dan Koeksistensi, (Yogyakarata: Program Studi Agama dan Lintas Budaya (Center for Religious and Cross-cultural Studies/CRCS) Sekolah Pascasarjana, Universitas Gadjah Mada, 2015), v
}

masyarakat dan negara dalam mengelola keragaman di satu tempat dan tempat lain. Ketiga, kapasitas masyarakat dan negara dalam mengelola keragaman seringkali diperlemah oleh kurangnya sinergi antar-elemen.

Beragam upaya sudah dilakukan untuk meredam permasalahan ini, beberapa di antaranya adalah pemerintah melalui Kementerian Agama menjembatani dialog antar umat beragama, advokasi terhadap umat, aliran dan/atau kelompok-kelompok minoritas korban kekerasan atas nama agama, membekukan ormas-ormas yang kerap berlaku anarkistis dengan mengatasnamakan agama dan yang tidak sejalan dengan semangat kebhinneka-an. Berangkat dari titik inilah, tulisan ini mencoba menawarkan sebuah strategi untuk menanamkan nilai-nilai moderat Islam ke dalam diri mahasiswa dengan memanfaatkan kegiatan belajar mengajar di kelas. Strategi yang ditawarkan adalah dengan melakukan revitalisasi Pendidikan agama di lingkungan Lembaga pendidikan Islam.Mengapa pendidikan Islam?Hal ini karena aktor-aktor utama pelaku kekerasan, tindakan anarkistis dalam konflik sosial berlatarbelakang agama adalah kelompok-kelompok yang berafiliasi pada lslam. 
Sehingga mau tidak mau, Pendidikan Islam mempunyai tanggungjawab moral dan social untuk turut mencari jalan keluarnya.

\section{A. Metode Penelitian}

Penelitian ini tergolong penelitian dengan pendekatan kualitatif dengan metode desktiptif analisis.Metode kualitatif merupakan suatu penelitian yang berorientasi pada fenomena atau gejala yang bersifat alami. Peneliti mengumpulkan data dan pengambilan dokumen pada situasi yang wajar dan alamiah, apa adanya.

Sumber data penelitian diambil dari bahan-bahan primer maupun sekunder, dalam hal ini yang menjadi bahan primer adalah buku Study Pendidikan Islam, Eksiklopedia Islam, AlQuran dan Hadis, artikel pendidikan Islam, Majalah, serta literature literatur lain sehingga layak dipandang sebagai documentary research. Dan bahan sekunder literatur yang mendukung penelitian ini.

\section{B. Pembahasan dan Hasil Penelitian}

\section{Pengertian Islam Moderat}

Kata moderat dalam bahasa Arab dikenal dengan alwasathiyah. Dalam Alquran merupakan kata yang terekam dari QS.al-Baqarah: 143. Kata al-Wasath dalam ayat tersebut, bermakana terbaik dan paling sempurna.Dalam hadis yang sangat populer juga disebutkan bahwa sebaikbaik persoalan adalah yang berada di tengah-tengah. Dalam artian dalam melihat dan menyelesaikan satu persoalan, Islam moderat mencoba melakukan pendekatan kompromi dan berada di tengah-tengah, begitupula dalam menyikapi sebuah perbedaan, baik perbedaan agama ataupun mazhab, Islam moderat selalu mengedepankan sikap toleransi, saling menghargai, dengan tetap meyakini kebenaran keyakinan masing-masing agama dan mazhab. Sehingga semua dapat menerima keputusan dengan kepala dingin, tanpa harus terlibat dalam aksi yang anarkis.

Moderasi adalah ajaran inti agama Islam.Islam moderat adalah paham keagamaan yang sangat relevan dalam konteks keberagaman dalam segala aspek, baik agama, adat istiadat, suku dan bangsa itu sendiri.Tak pelak lagi, ragam pemahaman keagamaan adalah sebuah fakta sejarah dalam lslam. Keragaman tersebut, salah satunya, disebabkan oleh dialektika antara teks dan realitas itu sendiri, dan cara pandang terhadap posisi akal dan wahyu dalam menyelesaikan satu masalah. Konsekuensi logis dari kenyataan tersebut adalah munculnya terma-terma yang mengikut di belakang kata Islam. Sebut misalnya, Islam 
Fundamental, Islam Liberal, Islam Progresif, Islam Moderat, dan masih banyak label yang lain.

Islam pada dasarnya adalah agama universal, tidak terkotak-kotak oleh label tertentu, hanya saja, cara pemahaman terhadap agama Islam. Diterima atau tidak, itulah fakta yang ada dewasa ini yang mempunyai akar sejarah yang kuat dalam khazanah Islam. Fakta sejarah menyatakan bahwa embrio keberagamaan tersebut sudah ada sejak era Rasulullah, yang kemudian semakin berkembang pada era sahabat, terlebih khusus pada era Umar bin Khattab. la kerap kali berbeda pandangan dengan sahabat-sahabat yang lain, bahkan mengeluarkan ijtihad yang secara sepintas bertentangan dengan keputusan hukum yang ditetapkan oleh Rasululullah Saw sendiri.

Mengacu pada makna etimologisnya, kategorisasi Islam moderat sebetulnya bisa saja dilakukan secara simplifikatif.Dari sejumlah gerakan Islam di Indonesia sejak prakemerdekaan hingga kini, terdapat kelompok yang dapat digolongkan sebagai lunak dan tidak ekstrem (moderat).Dalam sejarah kolonialisme di Indonesia ada Nahdhatul Ulama dan Muhammadiyah dapat disebut moderat, karena lebih menggunakan pendekatan pendidikan dan transformasi budaya.

Menurut Miftahudin ( 2010: 5) Karakter moderat Nahdhatul Ulama dan Muhammadiyah baru muncul setelah dibandingkan dengan gerakan Islam yang menggunakan kekerasan dalam perjuangan mengusir penjajah, sebagaimana ditunjukkan oleh gerakangerakan kelompok tarekat yang melakukan pemberontakan dengan kekerasan. ${ }^{5}$ Kategorisasi semacam itu pernah

pula dilakukan oleh Nasr Hamid Abu Zayd ketika memetakan posisi metodologis pemikiran imam Syafi'i.Abu Zayd menggolongkan Imam Syafi'l sebagai kelompok moderat-ekletik (1997).Pemetaan itu berdasar pada posisi Syafi'i yang berupaya mengambil jalan tengah antara metodologi $a h l a r-$ ra'y, yang lebih mengedepankan maslahat al-ammah (kemaslahatan umum) dan istihsan (prinsip-prinsip kebaikan yang kontekstual) dalam menjabarkan maksud dan tujuan syari'at, dan ahl al-hadis, yang lebih mengutamakan penjelasan Rasulullah SAW.yang terdokumentasi dalam hadis. Kelompok pertama direpresentasikan oleh Imam Abu Hanifah sedangkan yang

\footnotetext{
${ }^{5}$ Miftahudin, Islam Moderat Konteks Indonesia dalam persfektif Historis, Mozaik.Vol. V No.1 januari 2010. hal 5
} 
terakhir

oleh

Imam

Malik.MenurutAhmad Najib Burhani (2016,

$$
12
$$$$
\text { nopember) }
$$$$
\text { Syafi'i }
$$

dikategorikan

moderat

lantaran menawarkan metode tengah di antara dua ekstrimitas Hanafiyah dan Malikiyah. ${ }^{6}$

jika dilihat di dalam tafsirtafsir Al-Qur'an, makna din al-wasath (median or moderate religion) atau ummatan wasathan (moderate people) tidak digunakan untuk merujuk pada posisi tengah antara liberal dan radikal (teroris),

namun digunakan untuk menyatakan agama-agama yang berada di tengahtengah agama Kristen dan Yahudi atau yang "lembuh" dan "keras". Makna baru wasath (tidak liberal dan tidak radikal) telah terjadi sebagai justifikasi setelah

istilah Islam moderat beredar.

\section{Nilai - Nilai Islam Moderat}

Menurut Muchlis M. Hanafi (2013:3) Moderat dalam arti al-wasat sebagai model berfikir dan berinteraksi secara

seimbang di antara dua kondisi, sehingga sesuai dengan prinsip-prinsip Islam dalam berakidah, beribadah dan beretika, setidaknya bisa dilihat

${ }^{6}$ Ahmad Najib Burhani, “Moderate Islam Typology Missing the Point" dalam Jakarta Post", November 12, 2009 kesesuaiannya dengan

pertimbangan-pertimbangan dalam berperilaku dalam etika ${ }^{7}$ Islam yang senantiasamengacu pada maqasid alsyariah dan memperhatikan ummahat al-fadail. Secara lebih jelas bentuk moderasi lslam dapat dilihat dari aktualisasinya dalam mengatur tiga ruang, yaitu tadbir al-nafs, tadbir almanzil, dan tadbir al-mudun.

Pertama, tadbir al-nafs.Dalam hal ini seyogyanya seseorang harus mampu berfikir dan bertindak sesuai dengan maqasid al-syariah dan berdasarkan pertimbangan ummahat alfadail. Misalnya sikap seseorang dalam menyikapi umat agama lain. Seharusnya klaim kebenaran (truth claim) dalam keyakinan agama tidak perlu untuk diperdebatkan bahkan cenderung dipaksakan untuk diyakini orang yang berbeda agama. ${ }^{8}$ Hal ini malah akan mengganggu harmonisasi dalam kehidupan beragama sehingga memantik adanya konflik-konflik horizontal. Tindakan ini sesuai dengan

${ }^{7}$ Muchlis M. Hanafi, Moderasi lslam:
Menangkal Radikalisasi Berbasis Agama (Jakarta:
lkatan Alumni al-Azhar dan Pusat Studi al-
Qur'an, 2013), 3.
${ }^{8}$ Sikap ini merupakan cerminan dari
pribadi Gus Dur yang selama hidupnya
memperjuangkan harmonisasi dalam kehidupan
beragama, baginya pemaksaan atas pikiran
dan keyakinan orang tidak akan menghasilkan
apa-apa, kecuali membuat orang lain
menderita dan menghambat kemajuan
peradaban.


tujuan syariat karena menjaga kepentingan primer (al-daruriyyat) manusia dalam menjaga keyakinannya (hifzal-din) dan juga tindakan ini menunjukkan kebijaksanaan (al-hikmah) seseorang karena mampu menahan kehendaknya untuk tidak memaksa orang lain membenarkan keyakinannya.Menurut Ahmad Najib Burhani (2010:564) Disinilah sikap moderat menuai relevansinya, sehingga sikap seseorang akan lebih inklusif, toleran dan humanis sebagaimana menjadi karakter yang dimiliki orangorang moderat. ${ }^{9}$

Kedua, tadbir al-manzil.Maksud dari manzil disini tidak hanya sebatas lingkup keluarga, tetapi mencakup juga organisasi maupun institusi yang di dalamnya terdapat kumpulan orangorang yang mempunyai kepentingan bersama.Contoh dari aplikasi etika Islam dalam lingkup ini adalah pembagian harta warisan dalam keluarga. Dalam penentuan pembagian warisan di Indonesia boleh memilih antara tiga cara, berdasarkan hukum agama, perdata atau hukum adat. Adanya beberapa pilihan ini karena mempertimbangkan kondisi sosial yang ada di Indonesia.Misalnya penerimaan

${ }^{9}$ Ahmad Najib Burhani, “Al-Tawasut? Wa Al-l'tida $>$ : The NU and Moderatism In Indonesianlslam", Asian Journal of Social Science, vol 40 (2012), 564. hokum adat ini berdasarkan tradisi ('urf) yang sudah ada di masyarakat yang sudah menjadi sebuah keniscayaan. Egalitarianisme lslam memandang semua masyarakat adalah sama di hadapan Allah, sehingga semua adat yang ada di masyarakat bisa menjadi sumber hukum, tidak hanya adat yang ada di masyarakat Arab. Mahsun Fuad (2016:202) Semua adat ('urf) selama tidak bertentangan dengan prinsip ajaran Islam maka dalam batas-batas tertentu bisa diterima sebagai hukum Islam. ${ }^{10} \mathrm{Hal}$ ini jelas selaras dengan maksud dari tujuan syariah yaitu menjaga hak kepemilikan harta (hifz) almal) dan juga prinsip keadilan (aladalah) dalam mempertimbangkan pandangan akal dan wahyu.

Ketiga tadbir al-mudun aktualisasi tentang etika politik yang mana tujuan akhir adalah lahirnya kondisi Negara yang aman tentram dan damai, contoh dari penerapan etika ini adalah bagaimana menjaga stabilitas dan keutuhan Negara walaupun bukan berbentuk Negara lslam, kondisi ini sesuai dengan Negara Indonesia walaupun mayoritas memeluk lslam

\footnotetext{
${ }^{10}$ Mahsun Fuad, "Hukum lslam Indonesia: Dari Nalar Partisipatoris Hingga Emansipatoris"

dalam Akhmad Sahal dan Munawir Aziz (ed.), Islam Nusantara: dari Ushul Fiqh Hingga Paham Kebangsaan (Bandung: PT Mizan Pustaka, 2016), 202.
} 
namun Negara dibingkai dalam sistem tata keanekaragaman suku dan agama.Sehingga tingkat keharmonisan dan klaim kebeneran berdasarkan agama tertentu bisa dijaga dengan baik. Sikap yang demikian ini jelas selaras dengan karakteristik Islam moderat. Menurut Abou Fadl, Islam moderat memandang hukum abadi Tuhan yang ada di dalam al-Qur'an diturunkan secara spesifik terhadap persoalan tertentu berdasarkan persoalan-persoalan umat yang ada di zaman $\mathrm{Nabi}$, sehingga putusan spesifik ini harus dipahami secara konteks. Putusan spesifik ini bukanlah tujuan itu sendiri, melainkan tujuan itu untuk mencapai tujuan moral dari al-Qur'an seperti keadilan, keseimbangan, kasih sayang, kesetaraan, kebajikan dan lainlain."Dengan demikian maka pesan etis di dalam alQur'an menjadi pertimbangan dalam memutuskan sebuah hukum dengan mempertimbangkan kondisi sosiohistorisnya.Cara ini merupakan corak Islam di nusantara yang memang harus diperkuat sehingga nilai-nilai moderasi ini tetap terjaga.

$$
\text { Pendidikan dan lembaga }
$$
pendidikan sangat berperan menjadi

"Khaled M. Abou El-Fadl, Selamatkan Islam dari Muslim Puritan, terj. Helmi Mustofa (Jakarta: Serambi llmu Semesta, 2006), 189. penyebar benih radikalisme dan sekaligus penangkal Islam radikal.Studistudi tentang radikalisme dan terorisme mensinyalir adanya lembaga pendidikan Islam tertentu (nonformal) telah mengajarkan fundamentalisme dan radikalisme kepada para peserta didik. Belakangan ini, sekolah-sekolah formal juga mulai mengajarkan elemen-elemen Islam radikal,misalnya mengajarkan kepada murid untuk tidak menghormat bendera Merah Putih saat upacara bendera. $^{12}$

Menurut Habib Shulton Asnawi (2012: 29) Lembaga pendidikan sangat berperan mengajarkan ajaran Islam yang moderat untuk menanggulangi masuknya paham radikal dan fundamental di kalangan generasi muda. ${ }^{13}$ Islam moderat adalah nilai-nilai islam yang dibangun atas dasar pola pikir yang lurus dan pertengahan (i"tidal danwasath). Menurut Yusuf alQardhawi, wasathiyah (moderat) merupakan salah satu karakteristik yang tidak dimiliki ideologi lain.

\footnotetext{
${ }^{12}$ Berita ini dimuat pada 6 Juni 2011, terkait dua sekolah (SMP Allrysad Tawangmangu dan SD Al-Albani Matesih) berbasis agama yang melarang siswa menghormat Bendera Merah Putih di Karanganyar.

${ }^{13}$ Habib Shulton Asnawi, Hak Asasi Manusia Islam dan Barat (Studi Kritik Hukum Pidana Islam dan Hukuman Mati), Jurnal Supremasi Hukum 1, no. 1 (2012): 29
} 
Deradikalisasi adalah suatu program penanggulangan aksi-aksi kekerasan, teror dan radikalisme.Program ini melibatkan berbagai pihak dalam pelaksanaanya. Tidakhanya polisi dan aparat keamanan lainnya, tetapi juga kementerian, lembaga negara, dan civil society. perguruan tinggi, ulama, dan tokoh masyarakat, hingga institusi dasar dan terkecil dalam sistem sosial yaitu keluarga. Program deradikalisasi ini dibentuk bukan hanya karena reaksi terorisme yang semakin gencar, tetapi juga sebagai upaya untuk mengikis paham garis keras dalam beragama.

Program deradikalisasi ini dilakukan dengan berbagai cara, di antaranya:

1) Melakukan review kurikulum di berbagai tingkatan pendidikan untuk mengembangkan sikap, pengetahuan dan tindakan anti radikalisasi agama.

2) Melakukan seleksi terhadap para pendidik agar tidak mengajarkan Islam dengan konsep kaum radikalis.

3) Mengadakan diskusi terkait fundamentalisme, radikalisme dan multikulturalisme bagi pendidik,

4) Bekerjasama dengan ormas-ormas keagamaan yang memiliki pandangan Islam moderat.
Pendidikan dipilih sebagai cara yang paling ampuhuntuk menanggulangi radikalisme sejak dini karena sejak sekolah dasar, menengah sampai perguruan tinggi para peserta didik dibekali pendidikan agama Islam sebagai upayauntuk membina dan mengasuh anak didik agar senantiasa dapat memahami hakikat agama secara menyeluruh dan pada akhirnya dapat mengamalkan ajaran Islam dalam kehidupan sehari-hari. ${ }^{14}$ Jadi, pendidikan Islam dipandang penting karena merupakan salah satu pendidikan yang diharapkan mampu membentuk perilaku dan sikap para peserta didik di Indonesia yang multikultur dan multireligius.

Paradigma pendidikan agama Islam yang eksklusifdoktrinal yang selama ini diterapkan telah menciptakan kesadaran peserta didik untuk memandang agama lain secara berbeda, bahkan bermusuhan. Penyampaian pendidikan agama Islam kebanyakan juga terlalu menekankan doktrin keselamatan yang didasarkan pada kebaikan hubungan antara diri dengan Tuhan, dan kurang begitu

${ }^{14}$ Habib Shulton Asnawi, Kritik Teori Hukum Feminis Terhadap UU. NO. 1 tahun 1974 Tentang Perkawinan: Suatu Upaya dalam Menegakkan Keadilan HAM Kaum Perempuan, Al-Ahwal: Jurnal Hukum Keluarga Islam 4, no. 1 (2016): 55, 
memberikan tekanan antar sesama individu.

\begin{tabular}{ccr} 
Menurut Imron & \multicolumn{2}{r}{ Mashadi( } \\
2009:53) Padahal di
\end{tabular}
multikulturalisme ini, pendidikan agama Islam mestinya melakukan reorientasi filosofisparadigmatik tentang bagaimana memunculkan kesadaran peserta didik agar berwajah inklusif dan toleran. ${ }^{15}$ Negara Indonesia dikenal sebagai salah satu negara yang memiliki keanekaragaman yang besar. ${ }^{16}$ Oleh karena itu, perlu mengembangkan pendidikan multikultural dengan tujuan membangun pemahaman beragama yang inklusif, tidak merasa paling benar sendiri dan juga menciptakan kerukunan antar umat beragama karena pendidikan ini berbasis pada prinsip toleransi, demokrasi dan keadilan. Oleh karena itu, pengajaran Pendidikan agama Islam yang didapatkan sejak memasuki bangku sekolah diharapkan mengalami reformasi supaya generasi penerus bisa memahami agama dengan baik dan benar, melalui :

${ }^{15}$ Imron Mashadi, Pendidikan Agama Islam dalam Perspektif Multikulturalisme, "Reformasi PAl di Era Multikultural", (Jakarta: Balai Litbang Agama, 2009), 53

${ }^{16}$ Habib Shulton Asnawi, Politik Hukum Kesetaraan Kaum Perempuan Dalam Organisasi Masyarakat Islam Di Indonesia,\|Musãwa Jurnal Studi Gender Dan Islam II, no. 1, (2012): 48
1) Pendidik yang memiliki pengetahuan agama yang luas dan dapat mengajarkan pengetahuan agama tersebut secara dinamis

2) Strategi dan metode belajar yang memudahkan peserta didik dalam memahami ajaran agama.

3) Sarana dan prasarana yang bebas dari unsur radikalisme

4) Lingkungan sekolah yang mendukung dalam meminimalisir radikalisme.

Jadi, pendidikan Islam dipandang penting karena merupakan salah satu pendidikan yang diharapkan mampu membentuk perilaku dan sikap para peserta didik di Indonesia yang multikultur dan multireligius. Pendidikan agama yang apresiatif terhadap perbedaan agama dan perbedaan kultur akan memberikan dampak pada peserta didik menjadi manusia yang bersedia menghargai perbedaan dan menjadikan perbedaan sebagai bagian dari dalam kehidupannya. Hal ini yang menjadikan perspektif multikultur dan pluralisme dalam pendidikan agama harus dijadikan landasan para pendidik di Indonesia, sebab umat Islam Indonesia merupakan umat yang mayoritas multikultur.

\section{KESIMPULAN}


Peran Islam moderat untuk menanggulangi radikalisme di Lembaga Pendidikan Indonesia dengan cara deradikalisasi melalui pendidikan agama Islam yang multikultur. Pendidikan dipilih sebagai cara yang paling ampuh untuk menanggulangi radikalisme di Lembaga Pendidikan mulai dari SD sampai Perguruan Tinggi. Para peserta dibekali pendidikan agama Islam sebagai upaya untuk membina peserta didik agar dapat memahami hakikat agama secara menyeluruh dan akhirnya mampu membentuk perilaku dan sikap para peserta didik yang plural dan keterbukaan dengan menerapkan nilainilai moderattidak hanya melalui mata pelajaran, tetapi secara kultural harus ditanamkan ke seluruh aspek yang ada di lingkungan pendidikan.

\section{DAFTAR PUSTAKA}

Abidin Bagir, Zainal, "Pengantar" dalam Mohammad lqbal Ahnaf dkk. 2015. (ed.), Praktik Pengelolaan Keragaman di Indonesia Kontestasi dan Koeksistensi, Yogyakarata: Program Studi Agama dan Lintas Budaya (Center for Religious and Crosscultural Studies/CRCS) Sekolah Pascasarjana, Universitas Gadjah Mada,.

Aziz,Abdul, 2016. Menangkal Islamofobia Melalui Re-Interpretasi Alqur'an Vol. Jurnal Al-Ar'af, XIII, No. I, Januari - Juni
Hasanah, Iva dan Abdul Fatah, "Suara Simpang Kasus Sampang: Konflik Sunni-Syi'ah Perspektif Perempuan, Yogyakarata: Program Studi Agama dan Lintas Budaya” dalam Mohammad lqbal Ahnaf dkk (ed.), 2015. Praktik Pengelolaan Keragaman di Indonesia Kontestasi dan Koeksistensi, (Center for Religious and Crosscultural Studies/CRCS) Sekolah Pascasarjana, Universitas Gadjah Mada,.

Harahap, Syahrin, 1997. Islam Dinamis: Menegakkan Nilai-Nilai Ajaran Alqur'an dalam Kehidupan Modern di Indonesia, Yogyakarta; Tiara Wacana,

Imron Mashadi, 2009. Pendidikan Agama Islam dalam Perspektif Multikulturalisme, "Reformasi PAl di Era Multikultural", Jakarta: Balai Litbang Agama,.

Kholil, Moenawar, 1994. Al-qur'an dari Masa ke Masa, Solo: Ramdhani, Cet. ke-VII,.

M. Abou El-Fadl, Khaled, 2006. Selamatkan Islam dari Muslim Puritan, terj. Helmi Mustofa, Jakarta: Serambi llmu Semesta,.

M. Hanafi, Muchlis, Moderasi Islam: 2013. Menangkal Radikalisasi Berbasis Agama, Jakarta: Ikatan Alumni al-Azhar dan Pusat Studi al-Qur'an,.

Najib Burhani, Ahmad, "Moderate Islam Typology Missing the Point" 2009. dalam Jakarta Post", November 12,.

-------, “Al-Tawasut] Wa Al-l'tida>l: The NU and Moderatism In 
Indonesian Islam", 2012. Asian Journal of Social Science, vol 40.

Nata, Abduddin, 1996. Alqur'an dan Hadits: Dirasah Islamiyyah I (Jakarta: RajaGrafndo Persada,.

Nur lchwan, Moch, , 2016. "MUl, Gerakan Islamis dan Umat Mengambang", Maarif Vol. II, No. 2 Desember Jakarta: Maarif Institute for Culture and Humanity.

Sahal, Akhmad dan Munawir Aziz (ed.), 2016, Islam Nusantara: dari Ushul Fiqh Hingga Paham Kebangsaan, Bandung: PT Mizan Pustaka.

Shihab, M. Quraish, 1996. Membumikan Al-quran: Fungsi dan Peran Wahyu dalam Kehidupan Masyarakat, Bandung: Mizan,.

--------2013. Mukjizat Alquran: Ditinjau dari Aspek Kebahasaan, Isyarat Ilmiah, dan Pemberitaan Gaib, Bandung: Mizan,.
Shulton Asnawi, Habib, 2012, Hak Asasi Manusia Islam dan Barat, Studi Kritik Hukum Pidana Islam dan Hukuman Mati, Jurnal Supremasi Hukum 1, no. 1,.

2016. Kritik Teori Hukum Feminis Terhadap UU. NO. 1 tahun $1974 \quad$ Tentang Perkawinan: Suatu Upaya dalam Menegakkan Keadilan HAM Kaum Perempuan, Al-Ahwal: Jurnal Hukum Keluarga Islam 4, no. 1 ,

Shulton Asnawi, 2012Habib, Politik Hukum Kesetaraan Kaum Perempuan Dalam Organisasi Masyarakat Islam Di Indonesia, Musãwa Jurnal Studi Gender Dan Islam II, no. 1,.

Sulaiman, Muhammad, 1988, Al-Burhân 'Ala Wahy Alqur'an, diterjemahkan oleh Muhammad Habib M. dengan judul, Menyanggah Keraguan Terhadap Alqur'an, Solo: Ramdhani,. 